\title{
Corneal collagen cross-linking for progressive keratoconus in patients aged 9 to 14
}

\author{
Cross-linking corneano para ceratocone progressivo \\ em pacientes de 9 a 14 anos de idade
}

Fernando Plazzi Palis¹, Arthur Amaral Nassaralla ${ }^{2}$, Luis Gambi Deienno, Leonardo Pinheiro Teixeira', Belquiz R. do Amaral Nassaralla ${ }^{3}$

\begin{abstract}
Purpose: To determine the safety and efficacy of corneal collagen cross-linking (CXL) for progressive keratoconus in patients aged between 9 and 14 years old. Methods: Sixteen eyes of 11 patients ( 8 male and 3 female) with progressive keratoconus underwent epithelium-off CXL according to the standard Dresden protocol. Mean follow-up was 26 months (range, 12 to 60 months). Pre-and postoperative examinations included: uncorrected visual acuity (UCVA), best spectacle-corrected visual acuity (BSCVA), corneal topography, tonometry, refraction, corneal pachymetry, and endothelium cell count. Results: At the last follow-up visit, BSCVA improved by at least one Snellen line in six eyes (37.5\%) and remained stable in nine eyes (56.25\%). Two eyes (12.5\%) in habitual eye rubbers required a re-treatment due to keratoconus progression, at 15 and 28 months after first CXL. Manifest refraction and endothelium cell count remained stable. Topographic results showed statistically significant improvement in maximum K readings up to two years after CXL. However, this lost significance over time. No intraoperative complications were observed. Two eyes (12.5\%) presented grade one haze, which regressed after a month of topical steroid therapy. Conclusion: In this study of selected patients aged 9 to 14 , CXL was a safe and effective option for the treatment of progressive keratoconus. However, the effect in stemming the disease may not be long lasting and may require retreatment. A larger sample size and longer follow-up time are needed to verify this trend.

Keywords: Keratoconus/therapy; Collagen/radiation effects; Riboflavin/therapeutic use; Ultraviolet therapy; Cross-linking reagents; Child ClinicalTrials.gov ID- NCT01743443
\end{abstract}

\section{RESUMO}

Objetivo: Determinar a segurança e eficácia do cross-linking corneano (CXL) em pacientes de 9 a 14 anos de idade com ceratocone progressivo. Métodos: Dezesseis olhos de onze pacientes ( 8 homens e 3 mulheres) com ceratocone progressivo foram submetidos ao CXL, de acordo com o protocolo padrão de Dresden. A média do tempo de seguimento foi de 26 meses (variando de 12 a 60 meses). Os exames pré e pós-operatórios incluíram: acuidade visual sem correção (AVSC), melhor acuidade visual com correção (AVCC), topografia corneana, tonometria, refração, paquimetria corneana, e contagem de células endoteliais. Resultados: Na última visita de acompanhamento ambulatorial, a AVCC melhorou pelo menos uma linha na tabela de Snellen em 6 olhos (37,5\%) e permaneceu estável em 9 olhos (56,25\%). Dois olhos (12,5\%) de pacientes que coçam os olhos com frequência, exigiram retratamento devido à progressão do ceratocone, 15 e 28 meses após o primeiro CXL. A refração e contagem de células endoteliais mantiveram-se estáveis. Os resultados topográficos mostraram melhora estatisticamente significativa nos valores do K máximo até dois anos após o CXL. No entanto, houve perda de significância ao longo do tempo. Nenhuma complicação peroperatória foi observada. Dois olhos (12,5\%) apresentaram haze grau I, que regrediu após um mês de terapia com esteróide tópico. Conclusão: Neste estudo com pacientes selecionados, de 9 a 14 anos de idade, o CXL mostrou ser uma opção segura e eficaz para o tratamento do ceratocone progressivo. No entanto, o efeito pode não ser duradouro, podendo ser necessário um novo tratamento. Maior amostragem e maior seguimento são necessários para verificar esta tendência.

Descritores: Ceratocone/terapia; Colágeno/efeitos de radiação; Riboflavina/uso terapêutico; Terapia ultravioleta; Reagentes para ligações cruzadas; Criança

\footnotetext{
1 Instituto de Olhos de Goiânia, Goiânia, GO, Brazil.

${ }^{2}$ Faculdade de Medicina São Leopoldo Mandic, Campinas, SP, Brazil.

${ }^{3}$ Departamento de Córnea e cirurgia Refrativa, Instituto de Olhos de Goiânia, Goiania, GO, Brazil.

The authors declare no conflict of interest.

Received for publication 29/06/2015 - Accepted for publication 01/12/2015
} 


\section{INTRODUCTION}

$\mathbf{K}$ eratoconus is a progressive, frequently asymmetric, noninflammatory corneal thinning disorder characterized by changes in the structure and organization of corneal collagen. ${ }^{1}$ The disease classically manifests in the second decade of life when the cornea assumes an increasingly conical shape owing to its biomechanical instability. This leads to irregular astigmatism and subsequent decrease in visual acuity. ${ }^{(2)}$

Although keratoconus is most frequently diagnosed after adolescence, the corneal ectasia process starts at a much younger age. ${ }^{2}$ Pediatric keratoconus (keratoconus manifesting in childhood [less than 18 years of age] or adolescence [between 10 to 19 years of age]) exhibits several unique characteristics. Studies have shown that pediatric keratoconus demonstrates a higher rate ( $88 \%$ of keratoconus eyes) and speed of keratoconus progression compared to adult keratoconus. ${ }^{3,4}$

Recently, biomechanical properties of the cornea in different age groups are the focus of intense research for keratoconus. ${ }^{5}$ The progressive alteration of keratoconic corneal shape may be the result of elastic deformation. Corneal hysteresis is a measurement that purportedly reflects the viscoelastic properties of the cornea. Experimental ex vivo studies have shown an age-related change in corneal collagen fibril properties that may contribute to an increased stiffness of the cornea with age.

Corneal collagen cross-linking has been established as an effective surgical treatment to increase the biomechanical stability of the adult cornea in order to prevent the progression of the corneal ectasia occurring in keratoconus ${ }^{7-9}$ or following laser refractive surgery. ${ }^{10,11}$ This technique uses a combination of riboflavin (vitamin $\mathrm{B}_{2}$ ) and ultraviolet-A light (UVA) to induce cross-linking in stromal collagen. The role of riboflavin in this method is dual. It works as a photosensitizer for the induction of cross-links and protects the underlying tissues from the deleterious influence of UVA irradiation. ${ }^{7-9}$ It is the only therapeutic approach designed to halt the progression of the disease. ${ }^{7,8}$

The peer-reviewed literature, as well as our own experience with adult eyes that underwent CXL for progressive keratoconus and iatrogenic ectasia, demonstrated that the procedure was able to halt progression. Further, no endothelial cell loss, no cataract development, and no permanent side effects were observed in the adults. ${ }^{12-14}$

The aim of this study was to evaluate stability and functional response after riboflavin-UVA-induced cross-linking in a population of patients aged between 9 and 14 years old with progressive low stage (I e II) keratoconus.

\section{MethodS}

Sixteen eyes of eleven patients ( 8 male and 3 female) with progressive keratoconus, underwent epithelium-off CXL according to the standard Dresden protocol. Mean follow-up was 26 months (range, 12 to 60 months). According to the AmslerKrumeich classification ${ }^{10}$ of keratoconus disease, all eyes were classified as low stage keratoconus: 8 eyes $(50 \%)$ were stage I and 8 eyes $(50 \%)$ were stage II. An increase of 1.00 diopter (D) in maximum topographic $\mathrm{K}$-value $\left(\mathrm{K}_{\max }\right)$ and a reduction of corneal thickness with or without changes in uncorrected visual acuity (UCVA) and best-spectacle corrected visual acuity (BSCVA) within the last year were considered as indications of progression. All procedures were performed at the Goiania Eye Institute, Goiania, GO, Brazil, by a single surgeon (BAN), from January 2009 to December 2014.

Exclusion criteria were corneal thickness $<400 \mu \mathrm{m}$ at the thinnest point, severe vernal keratoconjunctivitis, severe dry eye, history of herpetic keratitis, concurrent autoimmune disease previous ocular surgery and central or paracentral opacities. Patients using contact lenses were asked to discontinue lens use for at least three weeks before each examination.

Preoperative and postoperative examinations included: UCVA, BSCVA, refraction, slit-lamp biomicroscopy, specular microscopy (Konan, Hyogo, Japan), corneal topography and pachymetry (Orbscan IIz, Technolas Perfect Vision GmbH).

The institutional ethics committee approved the study. All patients provided written informed consent in accordance with the Declaration of Helsinki after receiving a detailed description of the nature and risks of the procedure.

\section{Treatment}

Corneal CXL was conducted under sterile conditions in an operating room. All patients received a mild oral sedative (diazepam $5 \mathrm{mg}$ ) 30 minutes before surgery and two drops of topical $0.5 \%$ proximetacaine, 2 to 5 minutes before surgery. A wire eyelid speculum was placed for exposure. Corneal epithelium was removed by mechanical scraping over the central cornea (9.0-mm) with a blunt Paton spatula (Storz Ophthalmic Instruments, St Louis, USA).

The lid speculum was removed. Isoosmolar $0.1 \%$ riboflavin solution $(402.7 \mathrm{mOsmol} / \mathrm{L})$, which was generated by diluting vitamin $\mathrm{B}_{2}$-riboflavin-5-phosphate $0.5 \%$ with dextran T500 $20 \%$, was instilled to the cornea every 3 minutes for 30 minutes. A slitlamp examination, using a blue filter, ensured the presence of riboflavin in the anterior chamber.

The lid speculum was replaced. Fixation during irradiation was achieved by instructing the patient to focus on the lightemitting diode on the UVA emitter. The surgeon's thorough control ensured the patient's centration. Ultraviolet-A irradiation was performed for 30 minutes using a commercially available UVA system (UV-X, Peschke Meditrade) at a working distance of $5 \mathrm{~cm}$ with an irradiance of $3 \mathrm{~mW} / \mathrm{cm}^{2}$, corresponding to a surface dose of $5.4 \mathrm{~J} / \mathrm{cm}^{2}$. During irradiation, isoosmolar $0.1 \%$ riboflavin drops were applied every 5 minutes to ensure saturation of the cornea with riboflavin. A topical anesthetic agent $(0.5 \%$ proximetacaine was applied as needed.

After treatment, patients were medicated with topical moxifloxacin $0.3 \%$ drops 4 times a day for 5 days, and ketorolac tomethamine 3 times a day for 3 days. Soft therapeutic lens was applied until complete re-epithelialization of the cornea. Unpreserved artificial tears were recommended for mild irritation. Paracetamol-codeine pain medication was also prescribed, as needed, for the first 2 to 3 days. Fluorometholone eyedrops were then applied 3 times a day for 2 weeks.

Statistical analysis was performed using SPSS 17.0 (SPSS, Inc.) software package. The paired t-test was used to check the significance of the difference between two dependent groups for every continuous variable. The level of statistical significance was considered when $p$-value was lower than 0.05 .

\section{Results}

Sixteen eyes of 11 patients, 8 male and 3 female, with progressive keratoconus were included in this study. Mean age 
at the time of corneal collagen cross-linking was $10.38 \pm 1.7$ years (range, 9-14 years). Mean follow up was 26.63 months \pm 4 (range, 12-60 months). All treated eyes had early to moderate keratoconus, according to Amsler-Krumeich's classification. Eight eyes $(50 \%)$ were grade I and 8 eyes $(50 \%)$ were grade II keratoconus, with mean central keratometry readings of less than 53 diopters (D), absence of corneal scaring and minimum corneal thickness of greater than $400 \mu \mathrm{m})$. Documented evidence of keratoconus progression with reduced uncorrected (UCVA) or best corrected visual acuity (BCVA) by 1 line and/or worsening of refractive or corneal astigmatism, keratometry or cone apex power (CAP) by $0.75 \mathrm{D}$ over the $6-18$ months prior to CXL was noted in 7 patients (11 eyes).

\section{Refractive results}

Preoperatively, the mean spherical equivalent error (SEQ) was $-1.4(\mathrm{SD}: \pm 0.97 \mathrm{D})$, and the mean refractive astigmatism error (RAQ) was -2.31 (SD: $\pm 1.78 \mathrm{D})$. After $1,2,4$ and 5 years, a statistically significant reduction was observed in the mean spherical equivalent $(\mathrm{p}<0.000)$. A statistically significant decrease in mean refractive cylinder was also noted 1 and 5 years after CXL $(\mathrm{p}<0.000)$. Vector analysis showed an axis shift from 79.63 $(0-155)$ degrees to 27.5 (15-40) degrees 5 years after CXL, a difference that was statistically significant $(\mathrm{p}<0.000)$.

\section{Visual performance:}

UCVA and BCVA data were expressed in decimal scale and covering the entire follow-up. Mean UCVA was 0.24 before the procedure. Mean UCVA readings after CXL were as follow: 1 year after CXL, 0.28; 2 years after CXL was 0.29. At the last follow-up visit, UCVA improved by at least one Snellen line in 6 eyes $(37.5 \%)$ and remained stable in 9 eyes $(56.25 \%)$.

Before treatment, BCVA was 0.64. Mean UCVA after CXL were as follows: 1 year after CLX, 0.66; 2 years after CLX, 0.66, figure 1. UCVA and BCVA improvements were statistically significant $(\mathrm{p}<0.000)$ during the first year and remained unchanged between 2 and 5 years after CXL. Two eyes (12.5\%) in habitual eye rubbers required a re-treatment due to keratoconus progression, at 15 and 28 months after first CXL. One of them presented worsening of both uncorrected and corrected visual acuity.

\section{Graphic 1}

\section{Visual Performance}

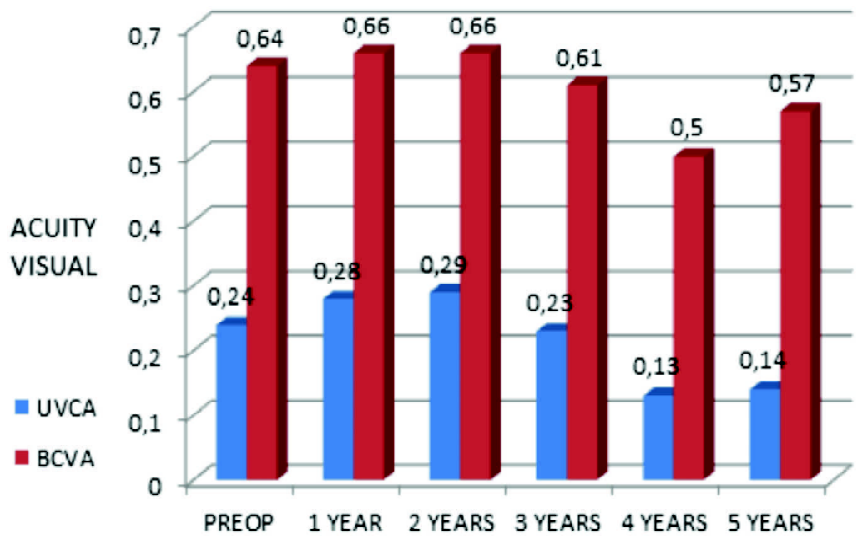

Preop = preoperative; UCVA: uncorrected visual acuity; BCVA: best corrected visual acuity

\section{Corneal pachymetry}

Mean corneal pachymetry by means of ORBSCAN optical pachymetry at baseline were $469.75 \pm 38.1 \mu \mathrm{m}$ (407-531). At 1 year, they decreased to $464.44 \pm 41.34(410-528)$ and at 5 years to $427.00 \pm 15.5$ (416-438), difference that was statistically significant $(\mathrm{p}<0.000)$.

\section{Topographic results}

Mean baseline simulated keratometry 2 and simulated keratometry 1 were 47.30D and 43.25D, respectively. At five years, these readings were 48.4 and 43.20 , respectively, a difference that was statistically significant $(p<0.000)$. Topographic results showed statistically significant improvement in maximum $\mathrm{K}$ readings up to two years after CXL. These results demonstrate a flattening effect of CXL on the keratoconic cornea. However, it lost significance overtime.

\section{Endothelium cell counts}

Mean baseline endothelial cell count was $2759 \pm 142.8$ cells/ $\mathrm{mm}^{2}$ (2510-2980). One year after CXL it was $2763 \pm 129.1$ cells/ $\mathrm{mm}^{2}$ (2580-2986); two years after CXL it was $2766 \pm 127.3$ cells/ $\mathrm{mm}^{2}$ (2588-2902); three years after CXL it was $2726 \pm 151.9$ cells/ $\mathrm{mm}^{2}$ (2598-2940); four years after CXL it was $2603 \pm 1.41$ cells/ $\mathrm{mm}^{2}$ (2602-2604); and at five years after CXL it was $2617 \pm 32.5$ cells $/ \mathrm{mm}^{2}(2594-2640)$.

\section{Complications}

No intraoperative complications were observed. Two eyes $(12.5 \%)$ presented grade one haze, which regressed after a month of topical steroid therapy. All retinal examinations were normal. No eyes lost more than one line of the BCVA.

\section{Discussion}

The diagnosis of keratoconus in children is made at a more advanced stage of the disease than in adults. This late diagnosis may be explained by the scarcity of functional complaints in children, especially before eight years of age and by the fact that visual loss is most often unilateral or very asymmetric. On the other hand, a recent study showed that corneal aberrations induced by keratoconus were at least partially offset by internal ocular structures. ${ }^{15}$ Presumably the high accommodative power in children may compensate for the distortions induced and delay the onset of functional complaints. Another hypothesis to consider is that the progression of keratoconus is explosive in children, with a short time between the onset of functional symptoms and the development of a severe form of keratoconus. ${ }^{16-18}$

Therefore, early detection of keratoconus in children with astigmatism is crucial because of the risk of rapid scalability, even at an early disease stage, close monitoring of children is necessary in order to detect any sign of scalability and offer appropriate treatment. ${ }^{19}$

Chatzis et al. $^{3}$ found that $88 \%$ of pediatric keratoconic patients demonstrated progression from their initial evaluation and Soeters et al. ${ }^{21}$ reported rapid progression of the keratoconus ranging from 2.6 D in several weeks to 5.0 D over a year. These findings suggest that treatment at onset of diagnosis may be appropriate as opposed to waiting for signs of progression as is commonly done in adults, because keratoplasty in the younger age group may be imminent.

A growing interest in the occurrence of keratoconus in children has emerged in recent years because of the development of new therapeutic options, especially the technique of corneal collagen cross-linking. 
Corneal CXL with riboflavin and UVA irradiation is a technique with a minimally invasive nature used for the stabilization of different types of corneal ectatic disorders. The aim of this technique is the augmentation of the mechanical rigidity of the cornea by inducing cross-links at the corneal stroma ${ }^{7-9}$ The removal of the epithelium has been recommended as an initial step of the CXL procedure since its lipophilic nature reduces the diffusion of riboflavin into the corneal stroma. ${ }^{8,9}$ Moreover, the epithelium may block UV rays. ${ }^{7}$ The photosensitizer riboflavin is applied to the de-epithelialized surface of the cornea and allowed to penetrate into the corneal stroma. ${ }^{7-10}$ The subsequent exposure of the cornea to UVA light is thought to result in photodynamic cross-linking when the riboflavin, excited by UVA, creates free radicals leading to crosslinking of collagen. ${ }^{7,8}$

The limitations in pediatric CXL are the pain induced by epithelial debridement and consequent temporary visual loss, which make postoperative management more complicated. The risk of postoperative complications (eg, estromal haze and infection $)^{21}$ and the variable period of visual recovery (2 to 6 months $)^{14}$ represent other limitations to consider in pediatric treatments.

In this series of patients, pain was controlled with topical and oral medication and use of therapeutic contact lens. No major complications were seen. There was no decrease in endothelial cell count, a finding supported by Wollensak and associates. ${ }^{22}$ Two eyes $(12.5 \%)$ presented grade one haze, which regressed after a month of topical steroid therapy.

In our study, at the last follow-up visit, BSCVA improved by at least one Snellen line in 6 eyes $(37.5 \%)$ and remained stable in 9 eyes $(56.25 \%)$. Only one eye lost one Snellen line in BSCVA and two lines in UCVA, two years after treatment. It was a 10-year old male patient at diagnosis with a progressive stage II keratoconus. However, in this patient, keratoconus stability was noted up to 34 months of follow up after CXL. Two eyes $(12.5 \%)$ in habitual eye rubbers required a re-treatment due to keratoconus progression, at 15 and 28 months after first CXL. Unfortunately, anterior segment OCT was not available in our setup, and is noted as a limitation of the study. Topographic results showed statistically significant improvement in Kmax up to two years after CXL. However, it lost significance over time.

Arora et al. ${ }^{23}$ included 15 eyes of 15 pediatric keratoconus patients (10 to 15 years) in their prospective study and reported results with follow up of a year. The authors did not document keratoconus progression prior to CXL and they based their decision of performing CXL on status of the fellow eye (all fellow eyes had advanced keratoconus demonstrating either hydrops or required corneal transplant). At the end of a year after CXL, mean flattening of apical keratometry $(\mathrm{K})$ was $1.01 \pm 2.40$ diopters, mean uncorrected distance visual acuity (UDVA) improved significantly from $20 / 200$ to $20 / 100(P=0.035)$ and mean corrected distant visual acuity (CDVA) from $20 / 70$ to $20 / 40(P=0.003)$.

Bakshi et al. ${ }^{24}$ in their retrospective study enrolled nine eyes of nine consecutive progressive keratoconic pediatric patients (11 to 17 years) and after CXL, patients were followed for up two years. Most patients (7 of 9,77.8 \%) showed long term stability. Improvement in CDVA, keratometry indices and refraction were noted, however they did not reach statistical significance, which may be due to the small sample size.

Vinciguerra et al. ${ }^{25}$ demonstrated outcomes of standard CXL in 40 eyes of 40 pediatric ( 9 to 18 years) patients in a prospective study with up to 2 years of follow up. After CXL, all keratoconic eyes were stabilized, furthermore there was a statistically significant improvement in CDVA, refraction and keratometric indices.

Prospective study report from Caporossi et al. ${ }^{26}$ (Siena CXL Pediatrics trial), involving 152 eyes of 77 patients (10 to 18 years) remains the largest series with the longest follow up (3 years). The study demonstrated after CXL, keratoconus stabilized and demonstrated rapid significant visual function improvement in the pediatric patients. There was a better and faster visual recovery in eyes with less than $450 \mu \mathrm{m}$ corneal thickness, compared with the thicker cornea group.

These publications have demonstrated that visual, refractive and topographic stabilization and improvements after pediatric CXL are similar to that report for adult treatment, with stability or improvement maintained for up two years follow up when treated with the standard protocol. Chatzis et al. ${ }^{3}$ found similar outcomes over two year, however, they noted some keratometric progression at the three years of follow up. It suggests that pediatric CXL may not provide long-term stability comparable to adult treatment and may require re-treatment especially in the subset of patients who persist in rubbing their eye.

Although only a few studies have reported CXL for pediatric keratoconus, our study shows the feasibility of this treatment in our small group of patients. A larger number of patients, randomized into control versus treated, would aid in determining the efficacy of this treatment for reversing symptoms and signs of keratoconus in pediatric patients. Our study is limited by the small number of eyes. Nevertheless, in this patient group, efficacy of CXL was noted as keratometric, visual, refractive values either stabilized or somewhat improved in most eyes.

\section{Conclusion}

In this study, CXL was a safe and effective option for the treatment of progressive low stage keratoconus in children. However, the effect of halting the disease may not be long lasting and may require re-treatment.

\section{REFERENCES}

1. Zadnik k, Barr JT, Gordon MO, Edrington TB. Biomicroscopic signs and desease severity in keratoconous. Collaborative Longitudinal Evaluation of Keratoconus (CLEK) Study Group. Cornea 1996; 15(2)139-46.

2. Rabinowitz YS. Keratoconus. Surv Ophthalmol. 1998; 42(4)297319.

3. Chatzis N, Hafezi F. Progression of keratoconus and efficacy of pediatric [corrected] corneal collagen cross-linking in children and adolescents. J Refract Surg. 2012;28(11)753-8.

4. Léoni-Mesplié S, Mortemousque B, Touboul D, Malet F, Praud D, Mesplié N, et al. Scalability and severity of keratoconus in children. Am J Ophthalmol. 2012;154(1)56-62.

5. Kirwan C, O'Keefe M, Lanigan B. Corneal hysteresis and intraocular pressure measurement in children using the Reichert ocular response analyser. Am J Ophthalmol. 2006; 142(6): 990-2.

6. Daxer A, Misof K, Grabner B, Ettl A, Fratzl P. Collagen fibrils in the human corneal stroma: structure and aging. Invest Ophthalmol Vis Sci. 1998; 39(3):644-8 .

7. Wollensak G, Spoerl E, Seiler T. Ribofloavin/ultraviolet-A-induced collagen cosslinking for the treatment of keratoconus. Am J Ophthalmol. 2003; 135(5):620-7. 
8. Spoerl E, Huhle M, Seiler T. Induction of cross-links in corneal tissue. Exp Eye Res. 1998; 66(1) :97-103.

9. Wollensak G, Spoerl E, Seiler T. Stress-strain measurements of human and porcine corneas after riboflavin-ultraviolet-A-induced cross-linking. J Cataract Refract Surg. 2003; 29(9):1780-5.

10. Hafezi F, Kanellopoulos J, Wiltfang R, Seiler T. Corneal collagen cross-linking with riboflavin and ultraviolet $\mathrm{A}$ to treat induced keratectasia after laser in situ keratomileusis. J Cataract Refract Surg. 2007; 33:2035-40.

11. Salgado J, Khoramnia R, Lohmann C, Winkler von Mohrenfels C. Corneal collagen cross linking in post-LASIK keratectasia. $\mathrm{Br} \mathrm{J}$ Ophthalmol. 2011; 95(4)493-7.

12. Spoerl D, Mrochen M, Sliney E, et al. Safety of UVA-riboflavin cross-linking of the cornea. Cornea. 2007;26(4):385-9.

13. Vinciguerra P, Albè E, Trazza S, Seiler T, Epstein D. Intraoperative and postoperative effects of corneal collagen cross-linking on progressive keratoconus. Arch Ophthalmol. 2009;127(10):1258-65.

14. Vinciguerra P Albè E, Trazza S, Rosetta P, Vinciguerra R, Seiler T, et al. Refractive, topographic, tomographic, and aberrometric analysis of keratoconic eyes undergoing corneal cross-linking. Ophthalmology 2009;116(3):369-78.

15. Schlegel Z, Lteif Y, Bains HS, Gatinel D. Total, corneal, and internal ocular optical aberrations in patients with Keratoconus. J Refract Surg. 2009;25(10 Suppl):S951-7.

16. Raiskup-Wolf F, Hoyer A, Spoerl E, Pillunat LE. Collagen crosslinking with riboflavin and ultraviolet-A light in keratoconus: Long-term results. J Cataract Refract Surg. 2008;34(5):796-801.

17. Wittig-Silva C, Whiting M, Lamoureux E, Lindsay RG, Sullivan LJ, Snibson GR. A randomized controlled trial of corneal collagen cross-linking in progressive keratoconus: Preliminary results. J Refract Surg. 2008;24(7):S720-5.

18. Gkika M, Labiris G, Kozobolis V. Corneal collagen cross-linking using riboflavin and ultraviolet-A irradiation: A review of clinical and experimental studies. Int Ophthalmol. 2011;31(4):309-19.

19. Elias RM, Lipener C, Uras R, Paves L, Keratoconus: prognosis factors. Arq Bras Oftalmol. 2005;68(4):491-4.
20. Soeters N, Van der Lelij A, van der Valk R, Tahzib NG. Corneal crosslinking for progressive keratoconus in four children. J Pediatr Ophthalmol Strabismus. 2011;48 Online:e26-9. doi: 10.3928/ 01913913-20110614-02

21. Zamora KV, Males JJ, Polymicrobial keratitis after a collagen cross-linking procedure with postoperative use of a contact lens; a case report. Cornea. 2009; 289(4):474-6.

22. Wollensak G, Spoerl E, Wilsch M, Seiller T. Endothelial cell camage after riboflavin-ultraviolet-A treatment in the rabbit. J Cataract Refract Surg. 2003;29(9):1786-90.

23. Arora R, Gupta D, Goyal JL, Jain P. Results of corneal collagen cross-linking in pediatric patients. J Refract Surg. 2012;28(11): 759-62.

24. Bakshi E, Barkana Y, Goldich Y, Avni I, Zadok D. Corneal Crosslinking for Progressive Keratoconus in Children: Our Experience. Int J Keratoco Ectatic Corneal Dis. 2012;1(1):53-6.

25. Vinciguerra P, Albé E, Frueh BE, Trazza S, Epstein D. Two-year corneal cross-linking results in patients younger than 18 years with documented progressive keratoconus. Am J Ophthalmol. 2012; 154 (3):520-6.

26. Caporossi A, Mazzotta C, Baiocchi S, Caporossi T, Denaro R, Balestrazzi A. Riboflavin-UVA-induced corneal collagen crosslinking in pediatric patients. Cornea. 2012;31(3):227-31.

\section{Corresponding author:}

Fernando Plazzi Palis, MD

Rua 9B, número 48 - Setor Oeste Zip code: 74110-120,

Goiânia, GO, Brazil.

Phone: (+5562) 3220-2500. I

E-mail: fernandopalis@hotmail.com 